\title{
Genetic parameter estimates for resistance to Enteric Septicemia of Catfish on Pangasianodon hypophthalmus
}

\author{
Dung T. P. Tran ${ }^{1,3 *}$, Phuc H. Tran ${ }^{2}$, Vu T. Nguyen ${ }^{2}$, Phuong H. Vo ${ }^{2}$, \\ Lien T. B. Huynh ${ }^{2}$, \& Sang V. Nguyen ${ }^{2}$ \\ ${ }^{1}$ Faculty of Biology, Ho Chi Minh City University of Education, Ho Chi Minh City, Vietnam \\ ${ }^{2}$ Research Institute for Aquaculture No. 2, Ho Chi Minh City, Vietnam \\ ${ }^{3}$ Department of Biology, Nong Lam University, Ho Chi Minh City, Vietnam
}

\begin{abstract}
ARTICLE INFO
Research Paper

Received: December 09, 2020

Revised: February 19, 2021

Accepted: February 26, 2021
\end{abstract}

Keywords

Disease resistance to ESC

Edwardsiella ictaluri

Genetic correlation

Heritability

Striped catfish

${ }^{*}$ Corresponding author

Tran Thi Phuong Dung

Email: dungttp@hcmue.edu.vn

\begin{abstract}
Genetic parameters were estimated for resistant traits against Enteric Septicemia of Catfish (ESC) on the first generation of selection on striped catfish. In total, 8,207 and 5,838 individuals from 147 and 130 full-sib families were challenged by Edwardsiella ictaluri causing ESC on fingerlings and tested growth in pond accordingly. Harvest body weight (HW), length (HL) and survival (SURGROW) from grow-out test and ESC resistant traits such as binary alive-dead survival (SUR) and time to dead (TIME) at different truncated points from challenged test of fingerlings were recorded. Heritability for each trait and genetic correlations among these recorded traits were estimated. High heritabilities were found for HW (0.48) and HL (0.47), and mostly from medium to high values were estimated for SURGROW (0.23), SUR $(0.13-0.40)$ and TIME $(0.25-0.39)$. Genetic correlations among different truncated SUR and TIME traits were almost highly positive (0.57 - 0.99). Genetic correlations among different truncated SUR and TIME traits with HW and SURGROW were low positive $(0.10-0.40)$. In summary, selection for ESC resistance would not negatively affect the growth in fingerling stage.
\end{abstract}

Cited as: Tran, D. T. P., Tran, P. H., Nguyen, V. T., Vo, P. H., Huynh, L. T. B., \& Nguyen, S. V. (2021). Genetic parameter estimates for resistance to Enteric Septicemia of Catfish on Pangasianodon hypophthalmus. The Journal of Agriculture and Development 20(1), 39-48. 


\title{
Các thông số di truyền ước tính cho tính trạng kháng bệnh gan thận mủ trên cá tra (Pangasianodon hypophthalmus)
}

\author{
Trần Thị Phương Dung ${ }^{1,3 *}$, Trần Hữu Phúc ${ }^{2}$, Nguyễn Thanh Vũ ${ }^{2}$, Võ Hồng Phượng ${ }^{2}$, \\ Huỳnh Thị Bích Liên ${ }^{2}$ \& Nguyễn Văn Sáng ${ }^{2}$ \\ ${ }^{1}$ Khoa Sinh Học, Trường Đại Học Sư Phạm TP.HCM, TP. Hồ Chí Minh \\ ${ }^{2}$ Viện Nghiên Cứu Nuôi Trồng Thủy Sản II, TP. Hồ Chí Minh \\ ${ }^{3}$ Bộ Môn Công Nghệ Sinh Học, Trường Đại Học Nông Lâm TP.HCM, TP. Hồ Chí Minh
}

\section{THÔNG TIN BÀI BÁO}

Bài báo khoa học

Ngày nhận: 09/12/2020

Ngày chỉnh sửa: 19/02/2021

Ngày chấp nhận: 26/02/2021

Từ khóa

Cá tra

Edwardsiella ictaluri

Hệ số di truyền

Kháng bệnh gan thận mủ

Tương quan di truyền

*Tác giả liên hệ

Trần Thị Phương Dung

Email: dungttp@hcmue.edu.vn

\section{TÓM TẮT}

Các thông số di truyền tính trạng kháng bệnh gan thận mủ được ước tính trên quần thể chọn giống thế hệ thứ 1 . Tổng cộng có 8.207 và 5.838 cá thể tương ứng thuộc 147 và 130 gia đình được cảm nhiễm vi khuẩn Edwardsiella ictaluri gây bệnh gan thận mủ ở cá giống và nuôi đánh giá tăng trưởng trong ao. Các tính trạng khối lượng (HW), chiều dài (HL) và tỉ lệ sống (SURGROW) sau nuôi tăng trưởng và tính trạng kháng bệnh gan thận mủ thông qua khả năng sống/chết dạng nhị phân (SUR) và thời gian sống theo giờ (TIME) theo các mức cắt ngang được thu thập và ước tính hệ số di truyền các tính trạng và tương quan giữa chúng. Hệ số di truyền cao cho tính trạng $\operatorname{HW}(0,48)$ và $\operatorname{HL}(0,47)$ và hầu hết từ trung bình đến cao cho các tính trạng SURGROW $(0,23)$, SUR $(0,13-0,40)$ và TIME $(0,25-0,39)$ được tìm thấy. Tương quan di truyền giữa SUR và TIME ở các cắt ngang hầu hết thuận và cao được ước tính $(0,57-0,99)$. Tương quan di truyền giữa SUR và TIME ở các cắt ngang với $\mathrm{HW}$ và SURGROW là tương quan thuận và thấp được ước tính $(0,10$ - 0,40). Do đó, chọn lọc tính trạng kháng bệnh không gây ảnh hưởng tiêu cực đến tính trạng tăng trưởng trên giai đoạn cá giống.

\section{1. Đặt Vấn Đề}

Cá tra (Pangasianodon hypophthalmus) đã trở thành đối tượng nuôi quan trọng và xuất khẩu chủ lực ở Việt Nam. Trong năm 2019, xuất khẩu cá tra đến 127 quốc gia trên thế giới và đạt kim ngạch hơn 1,9 tỉ USD. Diện tích thả nuôi là 6.600 ha (DOF, 2020). Tuy nhiên, trong những năm gần đây, việc sản xuất cá tra đang phải đối mặt với nhiều khó khăn như việc thâm canh hóa với mật độ nuôi cao đã làm cho bệnh trên cá xảy ra thường xuyên hơn (Tu \& ctv., 2008). Bệnh gan thận mủ do vi khuẩn Edwarsiella ictaluri (E. ictaluri) gây ra (Crumlish \& ctv., 2010 ) là một trong những bệnh phổ biến trên cá tra đã đưa vào danh mục phải kiểm dịch của Bộ Nông nghiệp và Phát triển Nông thôn. Bệnh xuất hiện hầu như ở mọi kích cỡ cá nhưng nhiều nhất ở cá nuôi dưới 4 tháng tuổi, tỉ lệ nhiễm ở cá nuôi kích cỡ nhỏ hơn 250 g là $24,4-25,2 \%$ và giảm dần theo sự tăng trọng lượng (Ly \& ctv., 2008). Hiện nay, các phương pháp phòng và trị bệnh chủ yếu bằng sử dụng kháng sinh và hóa chất là phổ biến. Điều này đã ảnh hưởng đến hiệu quả nghề nuôi, làm giảm chất lượng sản phẩm và tiềm ẩn nguy cơ như sự kháng thuốc ở vi khuẩn và dư lượng hóa chất, kháng sinh trong sản phẩm. Chọn giống theo phương pháp di truyền số lượng là giải pháp để nâng cao chất lượng con giống có khả năng kháng bệnh gan thận mủ. Cá tra chọn giống kháng bệnh sẽ làm giảm thiểu thiệt hại kinh tế do hao hụt, nâng cao tỉ lệ sống và giảm bớt rủi ro trong ương nuôi. Từ đó, giảm việc sử dụng thuốc, hóa chất, kháng sinh góp phần vào 
phát triển bền vững nghề nuôi cá tra phục vụ xuất khẩu (Trinh \& ctv., 2016).

Trinh \& ctv. (2016) đã công bố về hệ số di truyền tính trạng kháng bệnh gan thận mủ là 0,23 $\pm 0,11$, khác biệt có ý nghĩa so với zero (0) ở quần thể chọn giống ban đầu G0. Chương trình chọn giống đòi hỏi phải chọn lọc dựa trên các thông số di truyền tính toán được từ các gia đình qua nhiều thế hệ nhằm mang lại hiệu quả cao hơn. Do đó, việc thực hiện chọn giống cá tra kháng bệnh gan thận mủ thế hệ tiếp theo (G1) là cần thiết với mục đích là: (a) ước tính các thông số di truyền của tính trạng trên cá tra giống thế hệ G1 và (b) tìm mối tương quan di truyền về khả năng kháng bệnh với các tính trạng tăng trưởng và tî lệ sống nhằm đánh giá các tính trạng phục vụ chọn lọc.

\section{Vật Liệu và Phương Pháp Nghiên Cứu}

\subsection{Cá thí nghiệm}

Cá tra bố mẹ thuộc quần thể ban đầu $(\mathrm{G} 0)$ cho chọn giống kháng bệnh gan thận mủ được thành lập trong đề tài nghiên cứu giai đoạn 2012 - 2015 tại Viện Nghiên cứu Nuôi trồng Thủy sản II (Viện NC NTTS II). Quần thể G0 bao gồm nhóm chọn lọc (700 con, thuộc 120 gia đình) và nhóm đối chứng (131 con, thuộc 25 gia đình), khối lượng trung bình $8,0 \mathrm{~kg} / \mathrm{con}$. Các nhóm cá bố mẹ được lưu trữ phả hệ, giá trị kiểu hình tính trạng và giá trị chọn giống ước tính (Estimated breeding value - EBV) và được đánh dấu từ PIT (Passive Integrated Transponder) từng cá thể. Các cá thể thuộc quần đàn G0 được nuôi vỗ và cho sinh sản theo 4 dợt từ 22/08 - 09/10/2019 tại Trung tâm Quốc gia Giống Thủy sản Nước ngọt Nam Bộ thuộc Viện NC NTTS II để tạo quần đàn G1 (Bảng 1).

Sử dụng phương pháp ghép phối thứ bậc là 1 cá đực với 2 cá cái. Tổng cộng có 147 gia đình cá giống cho thí nghiệm cảm nhiễm (90 con bố phối với 147 con mẹ tạo ra 90 gia đình fullsib và 57 gia đình halfsib) và 130 gia đình cá giống cho thí nghiệm nuôi tăng trưởng (77 con bố phối với 130 con mẹ tạo ra 77 gia dình fullsib và 53 gia đình halfsib). Số lượng cá giống cho thí nghiệm cảm nhiễm là 8.207 cá thể (trung bình 56 con/gia đình, chia đều theo gia đình cho 2 bể thí nghiệm) với khối lượng trung bình $20,9 \mathrm{~g}$ và số lượng cá giống cho thí nghiệm tăng trưởng là 5.838 cá thể (trung bình 45 con/gia đình) với khối lượng trung bình 21,0 g (Bảng 1).

\section{2. Đánh dấu và thuần dưỡng cá cho thí nghiệm cảm nhiễm và nuôi tăng trưởng}

Ngay sau khi kết thúc ương cá giống khoảng 150 ngày, tiến hành gắn dấu cá giống trong thời gian 10 ngày, từ ngày $05 / 02 / 2020$ đến 14/02/2020. Cá được gắn dấu từ PIT vào cơ ở vị trí phía dưới vây lưng. Các gia đình được nuôi tăng trưởng đều có đại diện cho thí nghiệm cảm nhiễm. Sau khi đánh dấu tiến hành thuần dưỡng cá trước khi tiến hành như sau: (1) với thí nghiệm cảm nhiễm sau khi đánh dấu, cá được thả vào bể xi măng $15 \mathrm{~m}^{3}$ nuôi thuần dưỡng, có sục khí, mật độ thả khoảng 1 con/4 lít. Thuần dưỡng cá 10 ngày nước trước khi tiến hành thí nghiệm cảm nhiễm; (2) với thí nghiệm nuôi tăng trưởng sau khi đánh dấu, cá được thả vào giai lưới kích thước $15 \mathrm{~m}^{2}$ và lưu giữ khoảng 3 ngày sau đó thả nuôi trong ao.

\subsection{Thí nghiệm cảm nhiễm các gia đình cá giống}

Thí nghiệm thăm dò: được thực hiện dựa trên những thông số kĩ thuật tối ưu theo nghiên cứu của Trinh \& ctv. (2016) được trình bày tại bảng 1. Cá bệnh (cá cohabitant) được tạo ra bằng cách tiêm vi khuẩn E. ictaluri chủng Gly09M mật độ $1 \times 10^{6} \mathrm{CFU} / 0,2 \mathrm{~mL} /$ cá vào xoang bụng và cho sống chung với cá thí nghiệm. Sau đó, dung dịch vi khuẩn E. ictaluri được bổ sung một lần duy nhất vào bể thí nghiệm ở ngày thứ 2 sau khi cho cá cohabitant và cá thí nghiệm sống chung với nhau trong một bể. Thực hiện hai thí nghiệm thăm dò về lựa chọn tỉ lệ ghép cá Cohabitant (35\% và $50 \%)$ và mật độ vi khuẩn $\left(10^{5} \mathrm{CFU} / \mathrm{mL}\right.$ và $10^{6} \mathrm{CFU} / \mathrm{mL}$ ) cho vào bể cảm nhiễm sao cho đạt $10^{5} \mathrm{CFU} / \mathrm{mL}$. Mỗi nghiệm thức/thí nghiệm thăm dò lặp lại 2 lần.

Thí nghiệm cảm nhiễm chính: thí nghiệm cảm nhiễm 147 gia đình cá giống thực hiện với những thông số kĩ thuật tương tự ở thí nghiệm thăm dò nêu trên, thí nghiệm thực hiện trong 2 bể 16.000 $\mathrm{L}$, số lượng cá cho vào bể 1 , bể 2 và tổng hai bể tương ứng là 4.103, 4.104 và 8.207 con, mật độ cá là 0,26 con/L. Liều tiêm và tỉ lệ ghép cá cohabitant và liều bổ sung vi khuẩn vào nước bể cảm nhiễm lấy từ kết quả thí nghiệm thăm dò (Bảng 1). Thí nghiệm cảm nhiễm kết thúc khi cá không còn chết trong 5 ngày liên tục như khuyến cáo của Nordmo \& ctv. (1998) và tổng thời gian thí nghiệm là 23 ngày. 


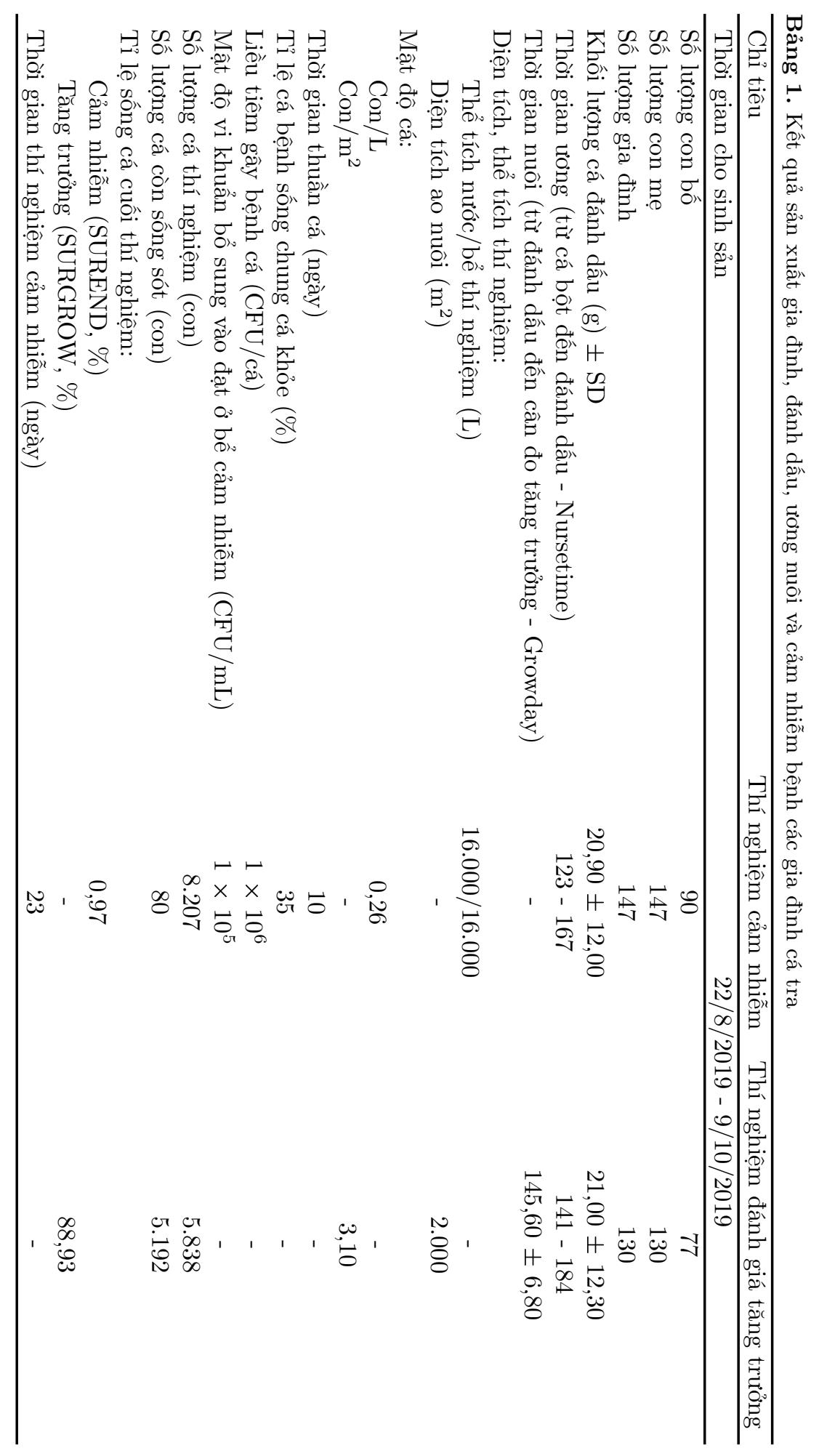




\subsection{Thí nghiệm nuôi chung đánh giá tính trạng tăng trưởng}

Tổng cộng có 5.838 cá thuộc 130 gia đình sau đánh dấu được thả nuôi trong ao $2.000 \mathrm{~m}^{2}$, mực nước 1,5 m, mật độ trung bình 3,1 con $/ \mathrm{m}^{2}$ (Bảng 1). Cá được cho ăn thức ăn viên cá tra (24 - $32 \%$ đạm). Hàng ngày cho ăn 2 lần vào lúc 7 giờ và 16 giờ. Khẩu phần ăn là $4-5 \%$ khối lượng thân trong 2 tháng đầu, 3 - 4\% khối lượng thân từ tháng thứ 2 đến thứ 5 và $2-3 \%$ khối lượng thân khi cá trên 5 tháng tuổi. Các kỹ thuật nuôi khác được áp dụng theo qui trình đã được hoàn thiện cho đánh giá tăng trưởng cho chọn giống tại Viện NC NTTS II. Đo chiều dài tổng và cân khối lượng từng cá thể (5.192 cá thể) khi cá nuôi sau 146 ngày.

\subsection{Thu thập và xử lí số liệu}

Thí nghiệm nuôi tăng trưởng: Mô hình tuyến tính hỗn hợp cá thể được sử dụng ước tính các thành phần phương sai tính trạng khối lượng $(\mathrm{HW})$ và chiều dài (HL) lúc thu hoạch bao gồm $\sigma_{\mathrm{A}}^{2}=$ phương sai di truyền cộng gộp, $\sigma_{\mathrm{C}}^{2}$ là phương sai ảnh hưởng của môi trường chung, $\sigma_{\mathrm{E}}^{2}$ là phương sai số dư và phương sai kiểu hình $\sigma_{\mathrm{P}}^{2}$ $=\sigma_{\mathrm{A}}^{2}+\sigma_{\mathrm{C}}^{2}+\sigma_{\mathrm{E}}^{2}$ là Khối lượng $\mathrm{ijkl}_{1}=\mu+\beta_{1} \times$ Nursetime $_{\mathrm{i}}+\mu+\beta_{2} \times$ Growday $_{\mathrm{j}}+$ cá thể $_{\mathrm{k}}+$ cá mẹl $_{1}+\mathrm{e}_{\mathrm{ijkl}}$ (Mô hình 1). Trong đó: Khối lượng ${ }_{\mathrm{ijkl}}$ là khối lượng của cá thể $\mathrm{k}$ khi thu hoạch, $\mu$ là trung bình của quần thể, $\beta_{1}$ là hệ số hồi quy của hiệp biến thời gian ương cho đến khi đánh dấu (Nursetime), $\beta_{2}$ là hệ số hồi quy của hiệp biến thời gian nuôi tăng trưởng (Growday), cá thể ${ }_{\mathrm{k}}$ là ảnh hưởng ngẫu nhiên của cá thể $\mathrm{k}$, cá mẹ là ảnh hưởng của môi trường ương riêng rẽ đến đánh dấu và $e_{i j k l}$ là ảnh hưởng ngẫu nhiên của số dư. Hệ số di truyền được ước tính là $\mathrm{h}^{2}=\frac{\sigma_{\mathrm{A}}^{2}}{\sigma_{\mathrm{A}}^{2}+\sigma_{\mathrm{C}}^{2}+\sigma_{\mathrm{E}}^{2}}$ và ảnh hưởng của môi trường ương riêng rẽ được ước tính là $\mathrm{c}^{2}=\frac{\sigma_{\mathrm{C}}^{2}}{\sigma_{\mathrm{A}}^{2}+\sigma_{\mathrm{C}}^{2}+\sigma_{\mathrm{E}}^{2}}$. Tương tự cho tính trạng HL. Đối với tính trạng tỉ lệ sống tăng trưởng (biến dạng nhị phân mã hóa sống: 1, chết: 0 tại thời điểm lúc thu hoạch) sử dụng mô hình (2) bên dưới để ước tính thông số di truyền.

Thí nghiệm cảm nhiễm: Tính trạng tỉ lệ sống thông qua khả năng sống/chết (SUR) theo cá thể trong thí nghiệm cảm nhiễm (biến nhị phân) mã hóa sống là 1 và chết là 0 lúc kiểm tra. Tính trạng thời gian sống theo cá thể tính theo giờ (TIME, biến liên tục), nếu cá thể còn sống tại một thời điểm cắt ngang trong thí nghiệm thì được mã hóa bằng thời gian sống trong toàn bộ thí nghiệm (là 528,5 giờ) và nếu chết tại thời điểm trước thời điểm cắt ngang trong thí nghiệm thì lấy thời gian cá sống đến thời điểm thực tế đó. Các tính trạng SUR và TIME được tính tại ba thời điểm trong quá trình cảm nhiễm lần lượt là thời điểm tổng số cá thí nghiệm sống $50 \%, 25 \%$ và cuối thí nghiệm với tỉ lệ sống 0,97\% tương ứng là SUR50, SUR25, SUREND và TIME50, TIME25 VÀ TIMEEND. Số liệu được xử lý bằng phần mềm ASReml V3 (Gilmour \& ctv., 2014). Mô hình tuyến tính hỗn hợp cá thể được dùng để ước tính các thành phần phương sai các tính trạng, nhưng không bao gồm "cá mẹ" là ảnh hưởng của môi trường ương riêng rẽ đến đánh dấu do mô hình không ước tính được nếu có bao gồm $\left(\sigma_{\mathrm{G}}^{2}=\right.$ phương sai di truyền, $\sigma_{\mathrm{E}}^{2}$ $=$ phương sai số dư và phương sai kiểu hình, $\sigma_{\mathrm{P}}^{2}$ $=\sigma_{\mathrm{G}}^{2}+\sigma_{\mathrm{E}}^{2}$ ) là $\mathrm{y}_{\mathrm{ijk}}=\mu+\beta_{\mathrm{i}} \times$ tuổi đánh dấu $\mathrm{i}_{\mathrm{i}}+$ bể ${ }_{j}+$ cá thể ${ }_{k}+\mathrm{e}_{\mathrm{ijk}}$ (Mô hình 2). Trong đó: $\mathrm{y}_{\mathrm{ijk}}$ là tình trạng (sống hoặc chết, SUR) và thời gian chết (TIME) của cá thể $\mathrm{k}$ ở các cắt ngang và khi kết thúc thí nghiệm cảm nhiễm, $\mu$ là trung bình của quần thể cá thí nghiệm, $\beta_{1}$ hệ số hồi quy của hiệp biến 'tuổi đánh dấu', bể định của hai bể thí nghiệm, cá thể ${ }_{\mathrm{k}}$ là ảnh hưởng ngẫu nhiên của cá thể $\mathrm{k}$ và $\mathrm{e}_{\mathrm{ijk}}$ là ảnh hưởng của số dư. Hệ số di truyền của tính trạng tỉ lệ sống và thời gian sống là $h^{2}=\frac{\sigma_{\mathrm{G}}^{2}}{\sigma_{\mathrm{G}}^{2}+\sigma_{\mathrm{E}}^{2}}$.

Uớc tính tương quan di truyền các tính trạng: Tương quan di truyền $\left(\mathrm{r}_{\mathrm{A}}\right)$ giữa hai tính trạng $\mathrm{HW}$ và $\mathrm{HL}$ được ước tính theo công thức $\mathrm{r}_{\mathrm{A}}=$ $\frac{\sigma_{12}}{\sqrt{\sigma_{1}^{2}}+\sqrt{\sigma_{2}^{2}}}(3)$. Trong đó: $\sigma_{12}$ là hiệp phương sai của ảnh hưởng di truyền cộng gộp của hai tính trạng, $\sigma_{1}^{2}$ và $\sigma_{2}^{2}$ lần lượt là phương sai ảnh hưởng di truyền cộng gộp của tính trạng 1 và 2 theo mô hình toán (1) (Falconer \& Mackay, 1996). Đối với tương quan di truyền $\left(\mathrm{r}_{\mathrm{G}}\right)$ giữa $H W$ và các tính trạng kháng bệnh gan thận mủ (SUR50, SUR25, SUREND và TIME50, TIME25 và TIMEEND) giống công thức (3) được sử dụng với phương sai và hiệp phương sai giống mô hình toán (2).

\section{Kết Quả và Thảo Luận}

\subsection{Thông tin cơ bản về các tính trạng khảo sát}

Kết quả qua hai thí nghiệm thăm dò (thí nghiệm về tỉ lệ ghép cá cohabitant: cá thí nghiệm và thí nghiệm liều bổ sung vi khuẩn vào bể 
cảm nhiễm sau hai ngày cho cá cohabitant và cá thí nghiệm sống chung) cho thấy: (1) tỉ lệ chết tương ứng cho 2 tỉ lệ ghép cá cohabitant $(50 \%$ và $35 \%$ ) là $20,0 \%, 31,1 \%$ và (2) tỉ lệ chết tương ứng 2 liều bổ sung vi khuẩn $\left(10^{5} \mathrm{CFU} / \mathrm{mL}\right.$ và $10^{6}$ $\mathrm{CFU} / \mathrm{mL}$ ) là $73,5 \%$ và $93,0 \%$. Kết quả cho thấy tỉ lệ ghép cá cohabitant : cá thí nghiệm 35\%: $65 \%$ và liều bổ sung vi khuẩn $10^{5} \mathrm{CFU} / \mathrm{mL}$ vào bể thí nghiệm vào ngày thứ 2 sau khi cho cá cohabitant sống chung với cá thí nghiệm là phù hợp cho thí nghiệm cảm nhiễm chính thức. Qua thí nghiệm cảm nhiễm chính thức các gia đình cá giống, hệ số biến thiên $(\mathrm{CV})$ tính trạng kháng bệnh gan thận mủ thông qua các chỉ tiêu sống/chết (SUR) và thời gian sống (TIME) theo các cắt ngang ở tỉ lệ sống $50 \%, 25 \%$ và cuối thí nghiệm với tỉ lệ sống 0,97\% (SUR50, SUR25, SUREND và TIME50, TIME25, TIMEEND) tương ứng là $109,14 \%, 141,84 \%, 508,25 \%$ và $58,42 \%, 56,66 \%$ và $34,94 \%$. Kết quả cho thấy $\mathrm{CV}$ của TIME50, TIME25 và TIMEEND thấp hơn CV của SUR50, SUR25 và SUREND. Nguyên nhân do tính trạng TIME của các gia đình theo dõi theo 3 giờ/lần, trong khi SUR của các gia đình tại thời điểm cắt ngang tính theo số lượng cá thề chết tại thời điểm cắt ngang đó nên mức độ biến thiên của tính trạng TIME thấp hơn SUR tại các thời điểm. Hệ số này cho tính trạng tỉ lệ sống lúc thu hoạch sau nuôi tăng trưởng (SURGROW) là 35,27\% (Bảng 2). Nguyen \& ctv. (2019b) công bố CV cho SUR60 cuối thí nghiệm cao hơn $(80,2 \%)$ trên cùng quần thể cá tra chọn giống kháng bệnh gan thận mủ ở thế hệ bố mẹ G0.

\subsection{Hệ số di truyền các tính trạng khảo sát}

Uớc tính bằng mô hình tuyến tính có bao gồm ảnh hưởng môi trường chung $\left(\mathrm{c}^{2}\right)$, hệ số di truyền $\left(\mathrm{h}^{2}\right)$ cho $\mathrm{HW}$ và HL cho quần thể G1 trong nghiên cứu này ở mức cao tương ứng là $0,48 \pm 0,17$ và $0,47 \pm 0,18$ và khác zero có ý nghĩa thống kê (Bảng 3). Kết quả này cho thấy nếu chọn lọc nâng cao tốc độ tăng trưởng thì hiệu quả mang lại sẽ cao. $\mathrm{h}^{2}$ cho HW trong nghiên cứu này trên G1 cao hơn $h^{2}$ cùng quần thể chọn giống kháng bệnh gan thận mủ nhưng ở thế hệ bố mẹ G0 là $0,35 \pm 0,12$ (Trinh \& ctv., 2016). Hệ số này cho HW cũng cao hơn với số liệu xử lý trên quần thể cá tra khác chọn giống nâng cao tốc độ tăng trưởng qua 3 thế hệ tại Việt Nam 0,34 $\pm 0,04$ (Nguyen \& ctv., 2019a). Ảnh hưởng môi trường chung $\left(\mathrm{c}^{2}\right)$ cho $\mathrm{HW}$ và $\mathrm{HL}$ trong nghiên cứu này $(0,18 \pm 0,07$ và $0,23 \pm 0,08)$ khác zero có ý nghĩa thống kê và cũng nằm trong khoảng công bố cho 2 tính trạng này ở cùng quần thể cá tra nhưng ở thế hệ khác (Trinh \& ctv., 2016; Nguyen \& ctv., 2019a).

Mô hình toán sử dụng trong nghiên cứu này có điều chỉnh ảnh hưởng không đồng nhất về thời gian sinh sản của các gia đình nhằm ước tính các thông số di truyền chính xác. Tuy nhiên, việc sinh sản của các gia đình không đồng nhất về thời gian cũng là hạn chế trong nghiên cứu này. Với số lượng gia đình half-sib đạt được cho số liệu cảm nhiễm bệnh gan thận mủ là 58 , chúng tôi đã sử dụng mô hình tuyến tính không bao gồm ảnh hưởng môi trường chung $\left(\mathrm{c}^{2}\right)$ để xử lý số liệu. Cách tiếp cận này cũng phù hợp khi Pham \& ctv. (2021b) cũng đã thử nghiệm mô hình có và không $c^{2}$ cho xử lý số liệu kháng bệnh gan thận mủ trên quần thể cá tra đã chọn lọc theo tính tăng tăng trưởng qua 3 thế hệ, cho ước tính hệ số di truyền với sai số thấp hơn. $\mathrm{h}^{2}$ cho tính trạng kháng bệnh thông qua sống/chết (SUR) ở mức trung bình, cao và thấp tương ứng là 0,20 , 0,40 và 0,13 cho các cắt ngang SUR 50, SUR 25 và SUREND. Trong khi đó, $\mathrm{h}^{2}$ cho tính trạng kháng bệnh thông qua thời gian sống (TIME) có hệ số di truyền ở mức trung bình, cao và trung bình tương ứng là $0,25,0,39$ và 0,35 (Bảng 3 ). Kết quả này cho thấy ở cắt ngang tỉ lệ sống $25 \%$ (SUR25 và TIME25) có hệ số di truyền cao nhất. Tất các giá trị $\mathrm{h}^{2}$ vừa nêu đều khác zero có ý nghĩa thống kê. Với hệ số di truyền này cho phép chúng ta kết luận hiệu quả mang ở mức trung bình đến cao nếu chúng ta thực hiện chọn lọc cho tính trạng kháng bện gan thận mủ. $\mathrm{h}^{2}$ cho SUR trong nghiên cứu này có cao hơn giá trị ước tính cùng mô hình toán trên cùng quần thể chọn giống kháng bệnh gan thận mủ ở thế hệ G0 với tỉ lệ sống ở $60,9 \%$ (0,19; Nguyen \& ctv., 2019b) và trên các quần thể chọn giống tăng trưởng khi cảm nhiễm bệnh gan thận mủ với tỉ lệ sống ở 8,0 - 11,8\% (0,11 - 0,13; Pham \& ctv., 2021b). $\mathrm{h}^{2}$ cho tính trạng thời gian chết (TIME) nhưng theo ngày cũng cho giá trị ước tính cao hơn SUR, 0,23 so với 0,19 (Nguyen \& ctv., 2019b). Khi tî̉ lệ sống giảm dần đến cuối thí nghiệm thì $\mathrm{h}^{2}$ cũng thấp hơn, điều này thấy rõ trong kết quả cảm nhiễm WSSV trên tôm thẻ chân trắng khi tỉ lệ sống giảm từ $92,1 \%$ xuống $42,8 \%$ thì $\mathrm{h}^{2}$ giảm từ 0,38 xuống 0,01 (Trinh \& ctv., 2016).

Hệ số di truyền $\left(\mathrm{h}^{2}\right)$ cho tỉ lệ sống lúc thu hoạch sau nuôi tăng trưởng (SURGROW) ở mức trung bình $(0,23 \pm 0,03)$ và khác zero có ý nghĩa thống 
Bảng 2. Kết quả về giá trị và sự biến thiên các tính trạng tăng trưởng và kháng bệnh cắt ngang theo tỉ lệ sống

\begin{tabular}{|c|c|c|c|c|c|c|}
\hline $\begin{array}{l}\text { Tính trạng quan } \\
\text { sát (đơn vị) }\end{array}$ & $\begin{array}{c}\text { Số cá } \\
\text { thể } \\
(\mathrm{n})\end{array}$ & $\begin{array}{l}\text { Trung } \\
\text { bình*1 }\end{array}$ & $\begin{array}{l}\text { Độ lệch } \\
\text { chuẩn*1 }\end{array}$ & $\begin{array}{c}\text { Hệ số biến thiên } \\
(\mathrm{CV}, \%)^{* 1}\end{array}$ & $\begin{array}{c}\text { Giá } \\
\text { trị } \\
\text { nhỏ } \\
\text { nhất }\end{array}$ & $\begin{array}{c}\text { Giá } \\
\text { trị lớn } \\
\text { nhất }\end{array}$ \\
\hline HL $(\mathrm{cm})$ & 5.192 & 38,45 & 3,49 & 9,07 & 21,00 & 48,50 \\
\hline $\mathrm{HW}(\mathrm{g})$ & 5.192 & 868,40 & 279,10 & 32,14 & 104,00 & 1973,00 \\
\hline SUR50 $(1 / 0)$ & 8.207 & 45,64 & 49,81 & 109,14 & 0,00 & 1,00 \\
\hline TIME50 (giờ) & 8.207 & 318,00 & 185,80 & 58,42 & 61,00 & 528,50 \\
\hline SUR25 $(1 / 0)$ & 8.207 & 25,55 & 36,24 & 141,84 & 0,00 & 1,00 \\
\hline TIME25 (giờ) & 8.207 & 237,00 & 134,30 & 56,66 & 61,00 & 528,50 \\
\hline SUREND $(1 / 0)$ & 8.207 & 0,97 & 4,93 & 508,25 & 0,00 & 1,00 \\
\hline TIMEEND (giờ) & 8.207 & 200,7 & 70,12 & 34,94 & 61,00 & 528,50 \\
\hline SURGROW (1/0) & 5.838 & 88,93 & 31,37 & 35,27 & 0,00 & 1,00 \\
\hline
\end{tabular}

*1: Đối với tính trạng sống/chết thì các số liệu trung bình, độ lệch chuẩn, hệ số biến thiên trong bảng tính toán theo tỉ lệ sống của các gia đình.

${ }^{2}$ HL: Chiều dài; HW: Khối lượng; SUR50, TIME50, SUR25, TIME25, TIMEEND: Kháng bệnh gan thận mủ; SUREND: Cảm nhiềm, SURGROW: Tăng tưởng.

Bảng 3. Các phương sai thành phần, hệ số di truyền ước $\left(\mathrm{h}^{2}\right)$ và ảnh hưởng môi trường chung $\left(\mathrm{c}^{2}\right)$ cho tính trạng tăng trưởng và kháng bệnh gan thận mủ cắt ngang theo tỉ lệ sống khác nhau

\begin{tabular}{|c|c|c|c|c|c|c|}
\hline \multirow{2}{*}{ Tính trạng ${ }^{1}$} & \multicolumn{4}{|c|}{ Phương sai thành phần } & \multirow{2}{*}{$\begin{array}{l}\text { Hệ số di truyền } \\
\left(\mathrm{h}^{2}, \mathrm{~TB} \pm \mathrm{se}\right)\end{array}$} & \multirow{2}{*}{$\begin{array}{c}\text { Hệ số } \mathrm{c}^{2} \\
\left(\mathrm{~TB} \pm \mathrm{se}^{* *}\right)\end{array}$} \\
\hline & $\sigma_{\mathrm{A}}^{2}$ & $\sigma_{\mathrm{C}}^{2}$ & $\sigma_{\mathrm{E}}^{2}$ & $\sigma_{\mathrm{P}}^{2}$ & & \\
\hline $\mathrm{HL}$ & 3,97 & 1,51 & 2,83 & 8,30 & $0,48 \pm 0,17$ & $0,18 \pm 0,07$ \\
\hline HW & $\begin{array}{c}25.532,50 \\
\sigma_{\mathrm{G}}^{2}\end{array}$ & $12.539,30$ & $\begin{array}{c}15.796,70 \\
\sigma_{\mathrm{E}}^{2}\end{array}$ & $\begin{array}{c}53.868,00 \\
\sigma_{\mathrm{P}}^{2}\end{array}$ & $0,47 \pm 0,18$ & $0,23 \pm 0,08$ \\
\hline SUR50 & 0,05 & - & 0,17 & 0,22 & $0,20 \pm 0,03$ & - \\
\hline TIME50 & $7.404,37$ & - & $22.192,80$ & $29.597,00$ & $0,25 \pm 0,04$ & - \\
\hline SUR25 & 0,05 & - & 0,08 & 0,13 & $0,40 \pm 0,05$ & - \\
\hline TIME25 & $6.191,78$ & - & $9.792,03$ & $15.984,00$ & $0,39 \pm 0,05$ & - \\
\hline SUREND & $0,33 \mathrm{e}^{-3}$ & - & $0,21 \mathrm{e}^{-2}$ & $0,24 \mathrm{e}^{-2}$ & $0,13 \pm 0,03$ & - \\
\hline TIMEEND & $1.521,16$ & - & $2.601,33$ & $4.122,5$ & $0,37 \pm 0,05$ & - \\
\hline SURGROW & 0,02 & - & 0,08 & 0,10 & $0,23 \pm 0,03$ & - \\
\hline
\end{tabular}

${ }^{1}$ HL: Chiều dài; HW: Khối lượng; SUR50, TIME50, SUR25, TIME25, TIMEEND: Kháng bệnh gan thận mủ; SUREND: Cảm nhiễm, SURGROW: Tăng tưởng.

kê (Bảng 3). Giá trị này gần tương đương $(0,27 \pm$ 0,03) với công bố của Nguyen \& ctv. (2019a) ước tính trên quần thể cá tra khác chọn giống nâng cao tốc độ tăng trưởng qua 3 thế hệ tại Việt Nam.

\subsection{Tương quan di truyền các tính trạng khảo sát}

Tương quan di truyền $\left(\mathrm{r}_{\mathrm{A}}\right)$ thuận giữa $\mathrm{HW}$ và HL và gần tuyệt đối $(0,99 \pm 0,01$; Bảng 4$)$ và hai tính trạng này có thể xem như là một. $\mathrm{r}_{\mathrm{G}}$ giữa $H W$ và SURGROW nghịch và ở mức $-0,13$ $\pm 0,12$, khác zero không có ý nghĩa thống kê và cho thấy chọn lọc nâng cao HW có thể không ảnh hưởng đến tỉ lệ sống lúc nuôi tăng trưởng. $\mathrm{r}_{\mathrm{G}}$ giữa $\mathrm{HW}$ với $\mathrm{HL}$ và $\mathrm{SURGROW}$ ở quần thể cá tra khác chọn giống qua 3 thế hệ nâng cao tốc độ tăng trưởng tại Việt Nam tương tự tương ứng là thuận cao $(0,94 \pm 0,01)$ và thuận $(0,27 \pm 0,09)$ được tìm thấy (Nguyen \& ctv., 2019a).

Tương quan di truyền $\left(\mathrm{r}_{\mathrm{G}}\right)$ giữa $\mathrm{HW}$ với SUR50, SUR25 và SUREND thuận và thấp tương ứng $0,16,0,10$ và 0,37 và chỉ có $\mathrm{r}_{\mathrm{G}}$ giữa $\mathrm{HW}$ với SUREND khác zero có ý nghĩa thống kê (Bảng 4). Trong khi đó, $\mathrm{r}_{\mathrm{G}}$ giữa HW với TIME50, TIME25 và TIMEEND thuận và cao hơn tương ứng là $0,26,0,33$ và 0,40 và tất cả các giá trị $r_{G}$ này khác zero có ý nghĩa thống kê. $\mathrm{r}_{\mathrm{G}}$ giữa SURGROW và SUR50, SUR25, SUREND, TIME50, TIME25 và TIMEEND thuận và cũng có chung xu hướng như HW, dao động trong khoảng 0,10 - 0,39. Tất cá các giá trị $\mathrm{r}_{\mathrm{G}}$ này khác zero có ý nghĩa thống kê, 


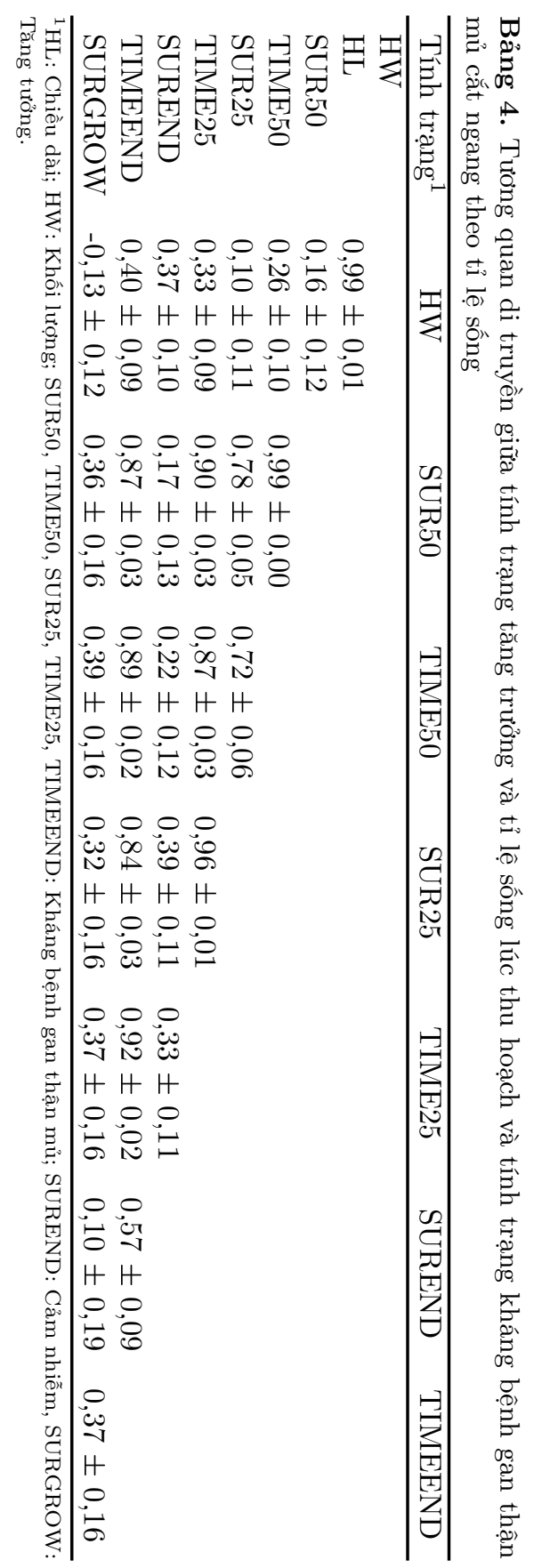

ngoại trừ giữa SURGROW với SUREND. Từ kết quả này cho thấy, nếu chọn lọc được áp dụng cho tính trạng kháng bệnh gan thận mủ thì có khả năng mang lại một phần hiệu quả hoặc không ảnh hưởng đến tính trạng tăng trưởng hay tỉ lệ sống sau nuôi tăng trưởng ở quần thể cá tra G1 này. $\mathrm{r}_{\mathrm{G}}$ xung quanh zero và thuận giữa $\mathrm{HW}$ và kháng bệnh thông qua SUR cũng đã công bố trên quần thể khác chọn giống tăng trưởng G3 ở Việt Nam (0,16 - 0,19; Pham \& ctv., 2021b) và khi xử lý chung G3 với cùng quần thể chọn giống kháng bệnh gan thận mủ trong nghiên cứu này nhưng thế hệ bố mẹ G0 (0,03; Nguyen \& ctv., 2019b). $\mathrm{Xu}$ hướng này cũng tìm thấy giữa $\mathrm{HW}$ và tính trạng thời gian sống (TIME) theo ngày khi xử lý chung G3 với cùng quần thể chọn giống kháng bệnh gan thận mủ trong nghiên cứu này nhưng thế hệ bố mẹ G0 (0,13; Nguyen \& ctv., 2019b).

Tương quan di truyền $\left(\mathrm{r}_{\mathrm{G}}\right)$ giữa tính trạng kháng bệnh dạng sống/chết (SUR), thời gian sống (TIME) ở các cắt ngang ở tỉ lệ sống $50 \%$, $25 \%$ và cuối thí nghiệm và giữa chúng với nhau là tương quan thuận và trong khoảng 0,17 0,99 (Bảng 4). Tương quan giữa 2 tính trạng ở cùng thời điểm cắt ngang gần như tuyệt đối (0,99 giữa SUR50 với TIME50; 0,96 giữa SUR25 với TIME25) và cao $(0,57$; giữa SUREND với TIMEEND). Trong các $\mathrm{r}_{\mathrm{G}}$ giữa $\mathrm{SUR}$ các cắt ngang (a), TIME các cắt ngang (b) và giữa SUR với TIME các cắt ngang $(\mathrm{c})$ thì xu hướng $\mathrm{r}_{\mathrm{G}}$ cao hơn ở (b) trong khoảng 0,87 - 0,92 và (c) trong khoảng $0,84-0,90$ so với (a) 0,78 giữa SUR50 và SUR25. Tương quan $\mathrm{r}_{\mathrm{G}}$ cao cho $\mathrm{SUR}(0,80$ - 0,99) giữa các cắt ngang trong quá trình cảm nhiễm bệnh đốm trắng trên tôm thẻ chân trắng (Trinh \& ctv., 2016). Trong nghiên cứu này, riêng SUREND có $\mathrm{r}_{\mathrm{G}}$ thấp với cùng SUR và TIME ở các cắt ngang khác, trong khoảng 0,17 - 0,39 và có 3 trong 5 giá trị $\mathrm{r}_{\mathrm{G}}$ khác zero không có ý nghĩa thống kê. Kết quả này cùng với hệ số di truyền thấp của SUREND $(0,13)$ ở Bảng 3 cho thây, có thể ở tính trạng sống/chết dạng nhị phân $1 / 0$ cuối thí nghiệm mà có tỉ lệ chết cao như thí nghiệm của nghiên cứu này (lên đến 99,03\%) có thể làm cho biến dị di truyền thấp và khi ước tính tương quan di truyền với các cắt ngang khác cũng xảy ra tương tự. Gjøen \& ctv., (1997) nghiên cứu bệnh trên cá hồi và Ødegård \& ctv. (2011) nghiên cứu các mô hình toán xử lý số liệu kháng bệnh thảo luận rằng tính trạng kháng bệnh cần được xem xét ở tỉ lệ sống xung quanh $50 \%$, do nếu đạt tỉ lệ sống thấp hơn thì một số gia đình không còn cá thể sống dẫn đến làm sai lệch kết quả ở tính trạng 
sống/chết. Trong nghiên cứu trên các thí nghiệm cảm nhiễm trên các quần thể cá tra chọn giống tăng trưởng G3 và với kết quả phân tích trên cùng quần thể cá tra chọn giống kháng bệnh với nghiên cứu này nhưng ở thế hệ bố mẹ G0, nhóm tác giả Pham \& ctv. (2021a và 2021b) thảo luận rằng thí nghiệm cảm nhiễm nên kết thúc ở tỉ lệ sống xung quanh $50 \%$ vì khi đó có phương sai kiểu hình và hệ số di truyền cao hơn, có thể phản ảnh đúng tính trạng kháng bệnh gan thận mủ hơn. Ngoài ra, Pham \& ctv. (2021a) cũng thảo luận rằng mô hình toán với tính trạng thời gian sống đến $50 \%$ có thể phản ảnh tốt sự mẫn cảm của cá tra với mầm bệnh Edwardsiella ictaluri gây bệnh gan thận mủ. Kết quả nghiên cứu này cho thấy phương sai kiểu hình $\left(\sigma_{\mathrm{P}}^{2}\right)$ cho cả SUR và TIME có xu hướng giảm từ cắt ngang $50 \%$ sang $25 \%(0,22$ so với 0,13 và $29.597,0$ giờ so với 15.984,0 giờ) và phương sai di truyền $\left(\sigma_{\mathrm{G}}^{2}\right)$ giữ nguyên giữa SUR50 $(0,05)$ và $\operatorname{SUR} 25(0,05)$, nhưng giảm giữa TIME50 $(7.404,37)$ và TIME25 $(6.191,78)$. Với kết quả trong nghiên cứu này về các thông số di truyền và các thảo luận của các tác giả vừa nêu về kháng bệnh trên cá hồi và cùng tính trạng trên cùng hoặc khác quần thể cá tra, cho thấy với tỉ lệ chết trong thí nghiệm cao $(99,03 \%)$ như hiện tại, chúng ta có thể xem xét chọn các tính trạng SUR50 hoặc SUR25 hay TIME50 để ước tính giá trị chọn giống ước tính (EBV) phục vụ cho chọn lọc.

\section{Kết Luận}

Hệ số di truyền tính trạng kháng bệnh gan thận mủ trên quần thể chọn giống G1 thông qua tính trạng sống/chết và thời gian sống theo giờ ở các cắt ngang tỉ lệ sống $50 \%$ và $25 \%$ ở mức từ trung bình đến cao $(0,20-0,40)$, cho thấy khả thi mang lại hiệu quả trung bình đến cao nếu thực hiện chọn lọc trên tính trạng này. Tương quan di truyền giữa các tính trạng kháng bệnh này từ cao đến gần tuyệt đối $(0,72-0,99)$ và có thể xem xét ước tính giá trị chọn giống cho tính trạng sống/chết ở cắt ngang $50 \%$ và $25 \%$ và tính trạng thời gian sống theo giờ ở cắt ngang $50 \%$ phục vụ cho chọn lọc. Chọn lọc theo tính trạng kháng bệnh gan thận mủ có thể mang lại hiệu quả một phần cho khối lượng và tỉ lệ sống lúc thu hoạch sau nuôi thương phẩm nhờ vào tương quan di truyền thuận tương ứng là 0,10 - 0,33 và $0,32-0,39$.

\section{Lời Cam Đoan}

Chúng tôi xin tuyên bố không có mâu thuẫn nào giữa các tác giả và đồng tác giả của bài báo.

\section{Lời Cảm Ơn}

Nghiên cứu được thực hiện trong khuôn khổ đề tài "Nghiên cứu chọn giống cá tra kháng bệnh gan thận mủ, 2019 - 2020" thuộc chương trình Công nghệ Sinh học Nông nghiệp và Thuỷ sản Bộ Nông Nghiệp và Phát triển Nông thôn. Chân thành cám ơn các anh chị thuộc Viện Nghiên cứu Nuôi trồng Thủy sản II đã tạo điều kiện cho nhóm nghiên cứu thực hiện các nghiên cứu liên quan.

\section{Tài Liệu Tham Khảo (References)}

Crumlish, M., Thanh, P. C., Koesling, J., Tung, V. T., \& Gravingen, K. (2010). Experimental challenge studies in Vietnamese catfish, Pangasianodon hypophthalmus (Sauvage), exposed to Edwardsiella ictaluri and Aeromonas hydrophila. Journal of Fish Diseases 33(9), 717-722.

DOF (Directorate of fisheries). (2020). Production results of the aquaculture sector in 2019. Retrieved December 09, 2020, from https://tongcucthuysan.gov.vn/Tint\%E1\%BB\%A9c/-Tin-v\%E1\%BA\%AFn/doctin/014196?2020-01-15=Banner+002.

Falconer, D. S., \& Mackay, T. F. C. (Eds.). (1996). Introduction to quantitative genetics ( $4^{\text {th }}$ ed.). Essex, England: Prentice Hall.

Gilmour, A., Gogel, B., Cullis, B., Welham, S., Thompson, R., Butler, D., Cherry, M., Collins, D., Dutkowski, G., \& Harding, S. (Eds.). (2014). ASReml user guide. Release 4.1 structural specification. Hemel Hempstead, UK: VSN International.

Gjøen, H. M., Refstie, T., Ulla, O., \& Gjerde, B. (1997). Genetic correlations between survival of Atlantic salmon in challenge and field tests. Aquaculture $158,277-288$.

Nguyen, V. T., Nguyen, S. V., Tran, P. H., Nguyen, V. T., \& Nguyen, N. H. (2019a). Genetic evaluation of a 15year selection program for high growth in striped catfish Pangasianodon hypophthalmus. Aquaculture 509, 221-226.

Nguyen, V. T., Nguyen, S. V., Trinh, T. Q., Nguyen, D. H., Nguyen, D. T., \& Nguyen, N. H. (2019b). Breeding for improved resistance to Edwardsiella ictaluri in striped catfish (Pangasianodon hypophthalmus): Quantitative genetic parameters. Journal of Fish Diseases 42(10), 1409-1417.

Nordmo, R., Ramstad, A., \& Riseth, J. H. (1998). Induction of experimental furunculosis in heterogenous test populations of Atlantic salmon (Salmo salar L.) by use of a cohabitation method. Aquaculture 162(1-2), 11-21. 
Ødegård, J., Madsen, P., Labouriau, R., Gjerde, B., \& Meuwissen, T. H. E. (2011). A sequential threshold cure model for genetic analysis of time-to-event data. Journal of Animal Science 89(4), 943-950.

Pham, K. D., Nguyen, S. V., Jørgen Ødegård, J., Gjøen, H. M., Klemetsdal, G. (2021a), Case study development of a challenge test against Edwardsiella ictaluri in Mekong striped catfish (Pangasianodon hypophthalmus), for use in breeding: Estimates of the genetic correlation between susceptibilities in replicated tanks. Journal of Fish Diseases 44(5), 553-561.

Pham, K. D., Ødegård, J., Nguyen, S. V, Gjøen, H. M, \& Klemetsdal, G. (2021b). Genetic analysis of resistance in Mekong striped catfish (Pangasianodon hypophthalmus) to bacillary necrosis caused by Edwardsiella ictaluri. Journal of Fish Diseases 44(2), 201-210.
Trinh, T. Q., Nguyen, D. H., \& Nguyen, V. T. (2016). Genetic parameters of resistant white spot symptoms trait on striped catfish (Pangasianodon hypophthalmus). Science and Technology Journal of Agriculutre \& Rural Development 23, 84-90.

Tu, D. T., Nguyen, N. T. N., Nguyen, T. Q., Duong, T. T. M., Nguyen, T. A., Shinn, A., \& Crumlish, M. (2008). Common diseases of pangasius catfish farmed in Vietnam. Global Aquaculture Advocate 11, 76-77. 